\title{
Removal of lead(II) ions by an adsorption process with the use of an advanced $\mathrm{SiO}_{2}$ /lignin biosorbent
}

\author{
Lukasz Klapiszewski", Przemysław Bartczak, Tomasz Szatkowski, Teofil Jesionowski* \\ Poznan University of Technology, Faculty of Chemical Technology, Institute of Chemical Technology and Engineering, \\ Berdychowo 4, PL 60-965 Poznan, Poland \\ "Corresponding authors: e-mail: lukasz.klapiszewski@put.poznan.pl; teofil.jesionowski@put.poznan.pl
}

\begin{abstract}
We demonstrate here that lignin can be successfully combined with silica to create a multifunctional material with considerable sorption capabilities. Experiments were carried out in which a silica/lignin hybrid was used for the removal of lead(II) ions from water solutions. Adsorption kinetics were also determined and preliminary regeneration tests were performed. The effectiveness of the adsorption process depends on the following parameters: contact time of adsorbent and adsorbate (equilibrium times: $5 \mathrm{~min}$ for concentration $25 \mathrm{mg} / \mathrm{L}, 10 \mathrm{~min}$ for 50 and $75 \mathrm{mg} / \mathrm{L}$, $60 \mathrm{~min}$ for $100 \mathrm{mg} / \mathrm{L}$ ), $\mathrm{pH}$ (optimal $\mathrm{pH}=5$ ) and adsorbent mass. The kinetics of the adsorption of lead(II) ions on the $\mathrm{SiO}_{2}$ /lignin biosorbent are best described by a pseudo-second-order model. Adsorption isotherms of lead(II) ions were also determined. The experimental data were found to be in agreement with the Langmuir model, and the maximal sorption capacity of the adsorbent with respect to lead(II) was $89.02 \mathrm{mg} / \mathrm{g}$.
\end{abstract}

Keywords: adsorption, $\mathrm{SiO}_{2} /$ lignin biosorbent, lead(II) ions, treatment of aqueous systems, adsorption kinetics.

\section{INTRODUCTION}

The intensive development of various branches of industry in recent decades has led to the emergence of serious problems of water pollution. Pollutants are among the major causes of progressive degradation of the natural environment. The toxic substances found in water systems may exhibit harmful effects on animals and plants, but also pose a serious threat to human health and even life. Special attention needs to be paid to metal ions, particularly lead(II) ions ${ }^{1,2}$. The growing problem of the presence of metal ions in aqueous systems has encouraged scientists to seek alternative methods for the removal of this type of contamination. One of the methods considered is adsorption, which offers high effectiveness and low implementation costs, ${ }^{3,5}$. Scientists are working on the development of new, more functional adsorbents which will exhibit better sorption capabilities along with possibilities of regeneration and reuse. A number of adsorbents have hitherto been used to remove lead(II) ions from aqueous solutions, including sandy loam soil ${ }^{6}$, temperate and semiarid surface soils ${ }^{7}$, rice husk ash $^{8}$, mandarin peel ${ }^{9}$, the fungus Aspergillus tamari $^{\mathbf{1 0}}$, and mustard husks ${ }^{\mathbf{1 1}}$.

Constant technological progress means that more and more new solutions are coming to light which make use of lignin and its derivatives ${ }^{12,13,14}$. Lignin may represent one of the potential cheap and easily accessible biosorbents for the removal of environmentally harmful metal ions ${ }^{15,16,17,18}$. For use as a sorbent, it is mainly obtained as a waste product of the paper industry, which afterwards is subjected to chemical modification to increase the quantity of functional groups ${ }^{19,20}$.

In the present work the possible use of a functional silica/lignin biosorbent in the removal of $\mathrm{Pb}$ (II) ions from model aqueous solutions was investigated. This material has been studied in detail, in terms of physicochemical and dispersive-morphological properties, in our previous papers ${ }^{21}{ }^{22}$. Moreover, recently published results prove that this material offers good sorption capabilities with respect to nickel(II) and cadmium(II) ions $^{23}$. However, more advanced investigations suggest that the silica/lignin material is even more effective at adsorbing lead(II) ions. These highly interesting results are discussed in the present work, and represent an innovative line of scientific investigation, published here for the first time. They provide relevant information of fundamental importance to the development of novel, functional sorbents of natural origin.

\section{EXPERIMENTAL}

\section{Preparation of silica/lignin hybrid material}

The silica/lignin hybrid material was obtained using a chemical combination of kraft lignin (Sigma-Aldrich, Germany) and Syloid 244 silica (WR Grace \& Co., USA) in a ratio of $1: 5(\mathrm{w} / \mathrm{w})$. This innovative method, proposed in our previous papers ${ }^{21}, 22,23,24$, makes it possible to obtain a system with unique physicochemical and dispersive-morphological properties. In the first step, lignin was activated with sodium periodate (Sigma-Aldrich, Germany) to improve its affinity to the silica support. Increased interaction between the precursors was also achieved by carrying out surface modification of the silica using $N$-2-(aminoethyl)-3-aminopropyltrimethoxysilane (Sigma-Aldrich, Germany) in a quantity of 5 parts by weight per 100 parts of silica. Details of the method of silica modification have appeared in the previous publications ${ }^{25,26}$.

\section{Batch adsorption experiments}

In this study, it was decided to use the silica/lignin hybrid material for the adsorption of lead(II) ions from aqueous systems. Lead nitrate, $\mathrm{Pb}\left(\mathrm{NO}_{3}\right)_{2}$ (Avantor ${ }^{\mathrm{TM}}$, Poland) was used as the precursor of lead(II) ions. It was determined how parameters such as contact time between adsorbent and adsorbate (1-180 min for model solutions of concentrations $25,50,75$ and $100 \mathrm{mg} / \mathrm{L} ; \mathrm{pH}$ $=5 ; \mathrm{m}=0.5 \mathrm{~g})$, reaction system $\mathrm{pH}(1,3,5,7,9$ for 
a model solution of concentration $50 \mathrm{mg} / \mathrm{L} ; 60 \mathrm{~min} ; 0.5 \mathrm{~g}$ ) and mass of sorbent $(0.5,1,2,3,4$ and $5 \mathrm{~g}$ for a model solution of concentration of $50 \mathrm{mg} / \mathrm{L} ; 60 \mathrm{~min} ; \mathrm{pH}=5$ ) influence the effectiveness of removal of lead(II) ions.

Prepared solutions of lead(II) ions $(100 \mathrm{~mL})$ in various concentrations were placed in conical flasks, and the silica/lignin hybrid sorbent was added to the model solution. The solution was mixed with the adsorbent using a magnetic stirrer (Ika Werke GmbH, Germany).

Atomic absorption spectroscopy (AAS analysis) was used to determine the quantity of lead(II) ions present in the filtrate after the adsorption process. This analysis was carried out using a Z-8200 spectrometer (Hitachi, Japan). Prior to analysis of the filtrates, standard curves of aqueous solutions of lead(II) ions were obtained. The efficiency of the process of adsorption of lead(II) ions on the hybrid material was determined using equation (1):

removal $\%=\left(\frac{C_{0}-C_{e}}{C_{0}}\right) \cdot 100 \%$

where $C_{0}$ and $C_{e}$ are respectively the initial and equilibrium concentrations of lead(II) ions $(\mathrm{mg} / \mathrm{L})$.

To determine the influence of $\mathrm{pH}$ on the effectiveness of removal of lead(II) ions, an appropriate quantity of $\mathrm{HNO}_{3}(0.1-1 \mathrm{M})$ or $\mathrm{NaOH}(0.1-1 \mathrm{M})$ (Sigma-Aldrich, Germany) was added to the model solution. The $\mathrm{pH}$ values were controlled with an EL20 pH-meter (Mettler Toledo, Switzerland).

\section{Kinetic study}

In order to carry out the tests it was necessary to determine the kinetics of the adsorption process. To determine the kinetics and the mechanism of this process, the equations of pseudo-first-order ${ }^{27}$ and pseudo-second-order ${ }^{28}$ models were used. Determination of the kinetics was necessary to calculate the value of $q_{t}$, the quantity of lead(II) ions adsorbed per unit time. This value was determined by equation (2):

$q_{t}=\frac{\left(C_{0}-C_{t}\right) \cdot V}{m}$

where $C_{0}$ and $C_{t}$ denote the concentration of lead(II) ions before and after the adsorption process $(\mathrm{mg} / \mathrm{L}), V$ is the volume of model solution (L), and $m$ is the mass of adsorbent used ( $\mathrm{g})$.

\section{Isothermal studies}

To determine the adsorption isotherms using the models of Freundlich ${ }^{29}$ and Langmuir ${ }^{30}$, it was necessary to determine the equilibrium concentration $\left(q_{e}\right)$ of lead(II) ions adsorbed on the adsorbent. The quantity of lead(II) ions adsorbed at equilibrium, $q_{e}(\mathrm{mg} / \mathrm{g})$, was calculated from equation (3):

$q_{e}=\frac{\left(C_{0}-C_{e}\right) \cdot V}{m}$

\section{Desorption tests}

Desorption of lead(II) ions from the hybrid materials was carried out using several concentrations of $\mathrm{HCl}$ solution (0.05-0.1 M; Sigma Aldrich, Germany) and water. The adsorbent undergoing desorption was placed in a beaker with $50 \mathrm{~mL}$ of water or hydrochloric acid of specified concentration. The solution was then mixed using a magnetic stirrer (Ika Werke GmbH, Germany) for $60 \mathrm{~min}$. After a set time, the mixture was filtered, and then analyzed using the AAS technique.

\section{RESULTS AND DISCUSSION}

\section{Adsorption efficiency}

In this study, a silica/lignin hybrid material (composed of 20 parts by weight of lignin per 100 parts of silica) was used as a potential biosorbent of lead(II) ions. This sorbent was prepared from the widely available waste biopolymer lignin, as described in our previous paper ${ }^{23}$. Combining lignin with silica produced a relatively cheap material with a high BET surface area of $223 \mathrm{~m}^{2} / \mathrm{g}^{23}$ and very favorable physicochemical properties. These characteristics motivated us to carry out further investigations into adsorption using this highly functional biosorbent.

The first stage consisted of adsorption tests. For this purpose, optimization of process time was carried out. Figure 1a shows a graph of the quantity of metal ions adsorbed from aqueous solutions of different concentrations $(25,50,75$ and $100 \mathrm{mg} / \mathrm{L})$ as a function of the contact time between the adsorbate and adsorbent.

The results confirmed that the initial adsorption process takes place very rapidly regardless of the concentration of metal ions, with a very high adsorption capacity of almost $100 \%$. For various concentrations of lead(II) ions, different adsorption equilibrium times were obtained $(25 \mathrm{mg} / \mathrm{L}: 5 \mathrm{~min} ; 50$ and $75 \mathrm{mg} / \mathrm{L}: 10 \mathrm{~min}$; and $100 \mathrm{mg} / \mathrm{L}: 60 \mathrm{~min})$.

An important objective of the analysis of the adsorption process was to determine the influence of medium $\mathrm{pH}$ on the efficiency of removal of lead(II) ions from model solutions. The results, shown in Figure 1b, presented that the process was least efficient in the most acidic medium $(\mathrm{pH}=1)$. As the system became more alkaline, there was a significant increase in the efficiency of the adsorption process, up to $\mathrm{pH}=5$, where the maximum process efficiency was attained. The dependence of the process efficiency on $\mathrm{pH}$ is mainly determined by the characteristic functional groups located on the adsorbent surface, as has been confirmed in previous publications ${ }^{31}$, 32. In an aqueous system the surface of the silica/lignin sorbent exhibits a negative charge, as has also been confirmed by electrokinetic stability studies ${ }^{21}$. This is important in the case of adsorption of positively charged lead(II) ions from model solutions.

It was also analyzed how the mass of sorbent used affects the efficiency of the process of adsorption of lead(II) ions from aqueous systems. Figure 1c shows a graph of process efficiency against quantity of biosorbent. The curves indicate that with an increase in the mass of biosorbent, the efficiency of the process also increases. This is due to the increase in the surface contact of the adsorbent, and consequently also in the quantity of characteristic functional groups present on the surface, which determines the adsorption capacity of the silica/lignin hybrid material.

\section{Kinetic study}

A significant objective of the work was to determine the kinetics of adsorption of lead(II) ions on the $\mathrm{SiO}_{2} /$ 

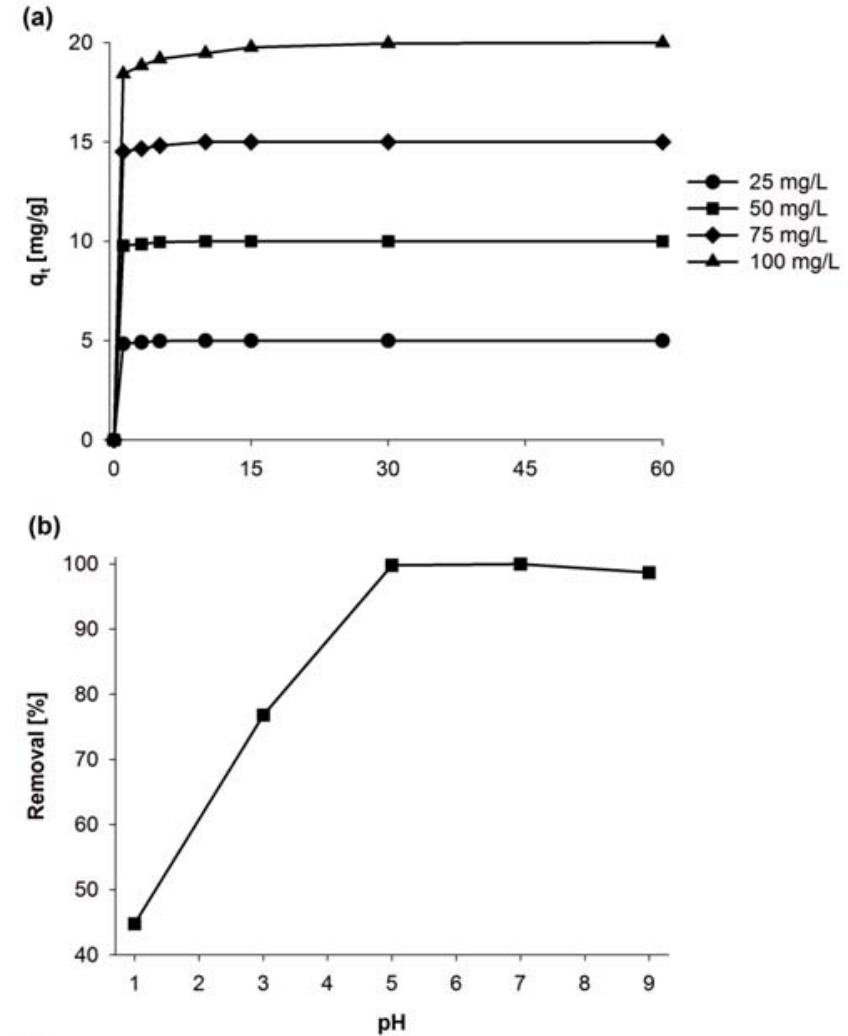

(c)

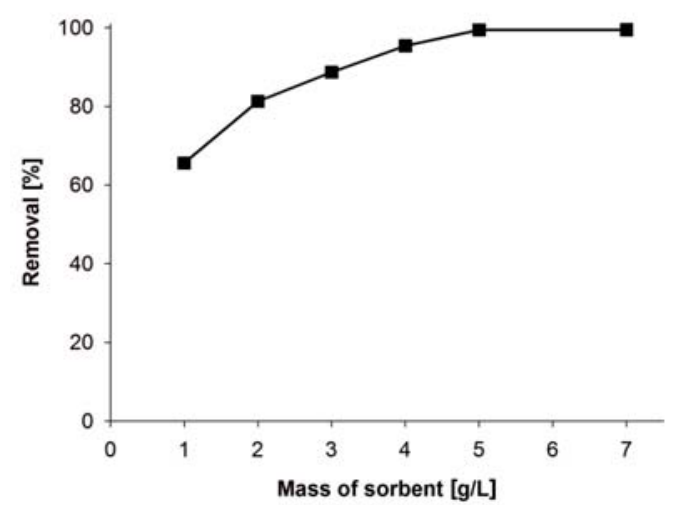

Figure 1. Effect of contact time (a), pH (b), and mass of adsorbent (c) on lead(II) ion removal using silica/ lignin biosorbent

lignin biosorbent, using pseudo-first-order ${ }^{27}$ and pseudo-second-order models ${ }^{\mathbf{2 8}}$. The kinetics of the pseudo-first-order model are described by equation (4):

$\log \left(q_{e}-q_{t}\right)=\log q_{e}-\frac{k_{1}}{2,303} \cdot t$

where $q_{e}$ and $q_{t}(\mathrm{mg} / \mathrm{g})$ are respectively the quantities of lead(II) ions adsorbed at equilibrium and at time $t$ (min), and $k_{1}(1 / \mathrm{min})$ is the rate constant for the pseudo-first-order rate equation.

Figure $2 \mathrm{a}$ shows a plot of $\log \left(q_{e}-q_{t}\right)$ against $t$, from which, by means of mathematical transformations, the constant parameters of the model were calculated (see Table 1).

Analysis of the results shows that the correlation coefficient $\left(r^{2}\right)$ determined for the pseudo-first-order model lies in the range $0.931-0.996$ for the tested concentrations of lead(II) ions.

It should be noted, however, that the quantities of adsorbed lead(II) ions $\left(q_{e, c a l}\right)$ obtained by calculation
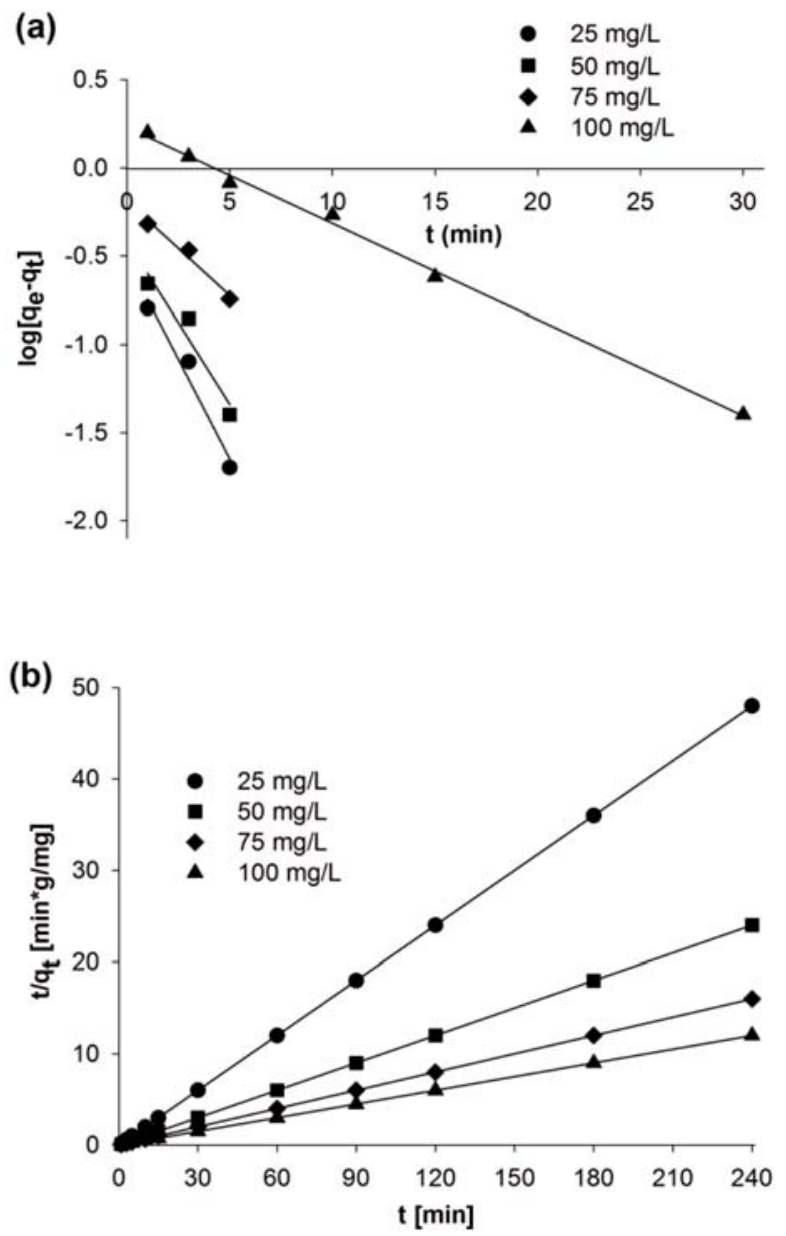

Figure 2. Pseudo-first-order (a) and pseudo-second-order (b) kinetic fit for adsorption of lead(II) ions on silica/ lignin hybrid biosorbent

using a pseudo-first-order model of adsorption kinetics deviate significantly from the experimental values $\left(q_{e, \text { exp }}\right)$.

A pseudo-second-order kinetic model is represented by equation (5):

$\frac{t}{q_{t}}=\frac{1}{k_{2} q_{e}^{2}}+\frac{1}{q_{e}} \cdot \mathrm{t}$

where $k_{2}(\mathrm{~g} /(\mathrm{mg} \cdot \mathrm{min}))$ is the rate constant for the pseudo-second-order rate equation.

The initial adsorption rate $h(\mathrm{mg} /(\mathrm{g} \cdot \mathrm{min}))$ is defined as follows (equation 6):

$h=k_{2} q_{e}^{2}$

The equilibrium concentration $\left(q_{e}\right)$ and the adsorption rate constant $\left(k_{2}\right)$ were calculated from the plot of $t / q_{t}$ against $t$ (Fig. 2b).

When the pseudo-second-order kinetic model has been applied to the adsorption of lead(II) ions, the correlation coefficient $\left(r^{2}\right)$ was found to be in the range 0.999-1.000 for all analyzed concentrations of ions. It should also be noted that the calculated values of $q_{e, c a l}$ are well correlated with the experimental values $q_{e, \exp }$. The adsorption rate constant $\left(k_{2}\right)$ decreased with increasing concentration of lead(II) ions. This is caused by the increasing competitiveness of lead(II) ions (adsorbate) for the active sites of the adsorbent. Thus, the pseudo-second-order kinetic model accurately describes the kinetics of adsorption of lead(II) ions on the silica/lignin biosorbent. The resulting 
Table 1. Pseudo-first-order and pseudo-second-order kinetic parameters for adsorption of lead(II) ions onto silica/lignin biosorbent

\begin{tabular}{|c|c|c|c|c|c|c|}
\hline \multirow{2}{*}{ Type of kinetic } & \multicolumn{2}{|c|}{ Parameters } & \multicolumn{4}{|c|}{$\begin{array}{c}\text { Lead(II) ions concentration } \\
{[\mathrm{mg} / \mathrm{L}]}\end{array}$} \\
\hline & symbol & units & 25 & 50 & 75 & 100 \\
\hline \multirow{4}{*}{ Pseudo-first order } & $q_{\text {e.exp }}$ & $\mathrm{mg} / \mathrm{g}$ & 5.00 & 10.00 & 15.00 & 20.00 \\
\hline & $q_{\text {e.cal }}$ & $\mathrm{mg} / \mathrm{g}$ & 0.30 & 0.39 & 0.64 & 1.70 \\
\hline & $k_{1}$ & $1 / \mathrm{min}$ & 0.52 & 0.43 & 0.25 & 0.13 \\
\hline & $r^{2}$ & - & 0.964 & 0.931 & 0.971 & 0.996 \\
\hline \multirow{4}{*}{ Pseudo-second order } & $q_{\text {e.cal }}$ & $\mathrm{mg} / \mathrm{g}$ & 5.01 & 10.00 & 15.02 & 20.02 \\
\hline & $k_{2}$ & $1 / \min$ & 12.29 & 7.37 & 2.57 & 0.32 \\
\hline & $r^{2}$ & - & 1.000 & 1.000 & 0.999 & 1.000 \\
\hline & $h$ & $\mathrm{mg} / \mathrm{g} \min$ & 307.42 & 736.68 & 577.61 & 130.13 \\
\hline
\end{tabular}

parameters of the adsorption process clearly indicate the high efficiency of the silica/lignin material used.

\section{Isotherm studies}

In the next stage of the study, the adsorption isotherms of lead(II) ions on the $\mathrm{SiO}_{2} /$ lignin system were determined. For this purpose two models were used: those of Freundlich ${ }^{29}$ and Langmuir ${ }^{30}$. The adsorption isotherms help to identify the mechanism of interaction between the adsorbate and adsorbent and to determine the sorption capacity of the biosorbent.

The linear forms of the Freundlich (equation 7) and Langmuir (equation 8) models are given below:

$\log q_{e}=\log K_{F}+\log C_{e}^{\frac{1}{n}}$

where $K_{F}(\mathrm{mg} / \mathrm{g})$ is a measure of adsorption capacity, and $1 / n$ denotes the intensity of adsorption (Fig. 3a).

$\frac{C_{e}}{q_{e}}=\frac{1}{b q_{m}}+\frac{C_{e}}{q_{m}}$

where $q_{m}$ is the maximum uptake of lead(II) ions ( $\mathrm{mg} / \mathrm{g}$ ), and $b(\mathrm{~L} / \mathrm{mg})$ is the adsorption equilibrium constant. The values of $b$ and $q_{m}$ (which are listed in Table 2) can be estimated from the intercept and gradient of the linear plot of $C_{e} / q_{e}$ vs. $C_{e}$ (Fig. 3b).

Table 2 shows the parameters of the Freundlich and Langmuir models. The experimental data for the adsorption of lead(II) ions on the $\mathrm{SiO}_{2}$ /lignin material are better described by the Langmuir isotherm model. This is confirmed by the high value of the correlation coefficient $\left(r^{2}=0.972\right)$. The maximum sorption capacity of the silica/lignin biosorbent was $89.02 \mathrm{mg} / \mathrm{g}$. The combination of the waste material lignin with $\mathrm{SiO}_{2}$ enables the preparation of a biosorbent with a significant capacity to remove lead(II) ions from aqueous systems.

The Freundlich isotherm model gave a correlation coefficient $\left(r^{2}\right)$ equal to 0.948 , which is also close to the value for the Langmuir model. This reflects the complex process of adsorption of lead(II) ions. In this case, adsorption can occur both within the pores (silica) and via the functional groups present on the surface of the hybrid (derived from lignin). The value of $1 / n$ is less than 1 , which confirms the proper course of the adsorption process.

Table 2. Isotherm constants of lead(II) ions adsorption on $\mathrm{SiO}_{2} /$ lignin biosorbent

\begin{tabular}{|c|c|c|c|c|c|}
\hline \multicolumn{3}{|c|}{ Freundlich parameters } & \multicolumn{3}{c|}{ Langmuir parameters } \\
\hline$R^{2}$ & $\begin{array}{c}K_{F} \\
{[\mathrm{mg} / \mathrm{g}]}\end{array}$ & $n$ & $R^{2}$ & $\begin{array}{c}q_{m} \\
{[\mathrm{mg} / \mathrm{g}]}\end{array}$ & $\begin{array}{c}b \\
{[\mathrm{~L} / \mathrm{mg}]}\end{array}$ \\
\hline 0.948 & 20.10 & 3.292 & 0.972 & 89.02 & 0.203 \\
\hline
\end{tabular}

(a)

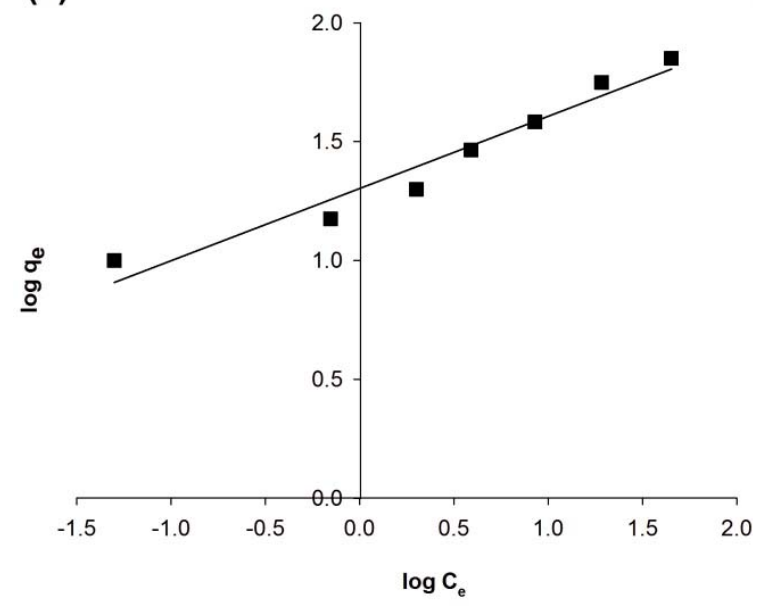

(b)

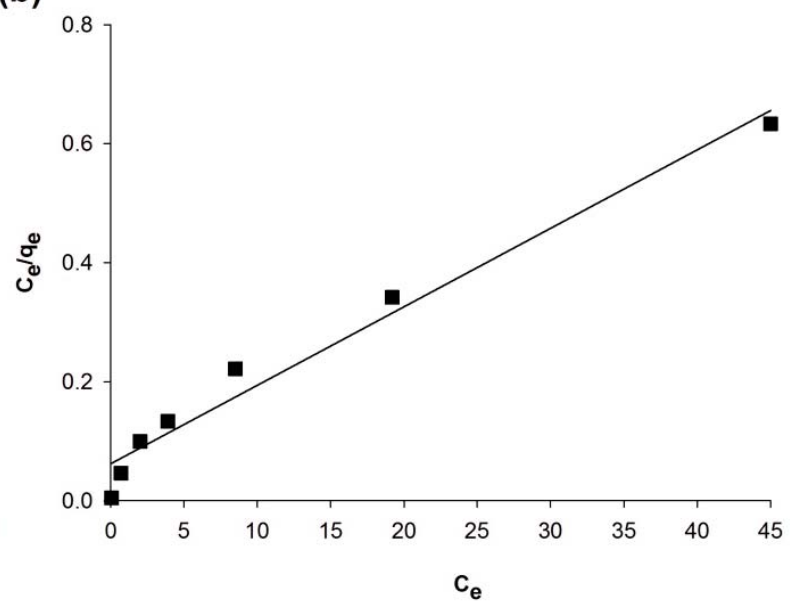

Figure 3. Nonlinear adsorption isotherm for lead(II) ions adsorbed on silica/lignin biosorbent

\section{Desorption tests}

A fundamental condition for the successful utilization of biosorbents is the possibility of their recovery, which enables further reuse of the materials. This is a key feature enabling the adsorption process to be considered as an economical and highly effective method for removing metal ions from aqueous systems. In this study, the desorbing agents used were water and hydrochloric acid at different concentrations: 0.05 and $0.1 \mathrm{M}$ (see Fig. 4). The use of water as a desorbing agent resulted in a very low degree of elution of metal ions (3.3\%). This might indicate a strong affinity between adsorbate and adsorbent. However, when hydrochloric acid was used as the regeneration medium, the tests produced satisfactory results. Notably, increasing the concentration of hydrochloric acid resulted in an increase in the 


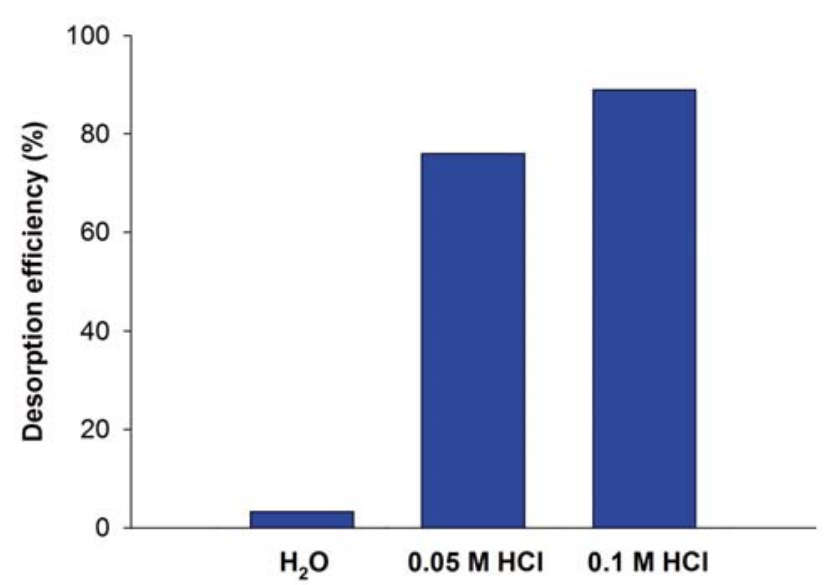

Figure 4. Desorption of lead(II) ions from spent biosorbent using $\mathrm{H}_{2} \mathrm{O}$ and $\mathrm{HCl}$

degree of desorption. The use of $0.05 \mathrm{M}$ hydrochloric acid gave a recovery ratio of approximately $76 \%$, while for $0.1 \mathrm{M} \mathrm{HCl}$ the recovery ratio was $89 \%$.

After the desorption process the silica/lignin biosorbent is ready to be used for further adsorption processes, which is crucial both from an economic standpoint and in terms of the development of "green" technologies for the removal of metal ions from aqueous systems.

The silica/lignin hybrid can successfully compete with other synthetic sorbents or systems classified as low-cost sorbents. Its advantages include its very good sorption properties and the high efficiency of lead(II) ion removal. Additionally, the use of relatively cheap materials will have a positive impact on the economics of the process.

\section{CONCLUSIONS}

In this study, a functional $\mathrm{SiO}_{2}$ /lignin hybrid material has been used as a biosorbent for lead(II) ions. It was found that the effectiveness of removal of the $\mathrm{Pb}(\mathrm{II})$ ions was strongly influenced by the parameters of the process, most importantly the contact time between adsorbate and adsorbent, the $\mathrm{pH}$ of the system, and the mass of sorbent. A very interesting finding is that during optimization of the process, each parameter achieved $100 \%$ efficiency. The experimental data fit much better to the pseudo-second-order kinetic model, which was used to determine the basic kinetic parameters of the adsorption process. The experimental data obtained for adsorption isotherms substantially correspond to the Langmuir model. The maximum sorption capacity was $89.02 \mathrm{mg}$ of lead(II)/g. In desorption tests, the use of $0.1 \mathrm{M} \mathrm{HCl}$ was sufficient to achieve a high degree of elution of the adsorbed metal, which demonstrates the possibility of regeneration and reuse of the biosorbent. The analyzed hybrid system, based on the relatively cheap waste product lignin, combined with silica, undoubtedly has potential applications as a very effective adsorbent of inorganic pollutants.

\section{ACKNOWLEDGMENTS}

The study was supported by research grant no. 03/32/ DSMK/0510 from Poznan University of Technology.

\section{LITERATURE CITED}

1. Patrick, L. (2006). Lead toxicity, review of the literature. Part 1: Exposure, evaluation, and treatment. Altern. Med. Rev. 11(1), 2-21.

2. Jaishankar, M., Tseten, T., Anbalagan, N., Mathew, B.B. \& Beeregowda, K.N. (2014). Toxicity, mechanism and health effects of some heavy metals. Interdiscipl. Toxicol. 7(2), 60-72. DOI: 10.2478/intox-2014-0009.

3. Guo, X., Zhang, S. \& Shan, X. (2008). Adsorption of metal ions on lignin. J. Hazard. Mater. 151(1), 134-142. DOI: 10.1016/j.jhazmat.2007.05.065.

4. Ciesielczyk, F., Bartczak, P., Wieszczycka, K., Siwińska-Stefańska, K., Nowacka, M. \& Jesionowski, T. (2013). Adsorption of $\mathrm{Ni}(\mathrm{II})$ from model solutions using co-precipitated inorganic oxides. Adsorption 19(2), 423-434. DOI: 10.1007/ s10450-012-9464-5.

5. Huang, G., Wanga, D., Mab, S., Chen, J., Jiang, L. \& Wang, P. (2015). A new, low-cost adsorbent: Preparation, characterization, and adsorption behavior of $\mathrm{Pb}(\mathrm{II})$ and $\mathrm{Cu}(\mathrm{II})$. J. Colloid Interface Sci. 445, 294-302. DOI: 10.1016/j. jcis.2014.12.099.

6. Miretzky, P., Munoz, C. \& Carrillo-Chavez, A. (2007). A sandy loam soil as a natural control for $\mathrm{Pb}$ contamination. Environ. Chem. Lett. 5(3), 131-136. DOI: 10.1007/s10311-007-0093-2.

7. Safari Sinegani, A.A. \& Araki, H.M. (2010). The effects of soil properties and temperature on the adsorption isotherms of lead on some temperate and semiarid surface soils of Iran. Environ. Chem. Lett. 8(2), 129-137. DOI: 10.1007/s10311-0090199-9.

8. Pei-Sin, K., Siew-Ling, L., Sie-Tiong, H., Yung-Tse, H. \& Siew-Teng, O. (2014). Removal of hazardous heavy metals from aqueous environment by low-cost adsorption materials. Environ. Chem. Lett. 12(1), 15-25. DOI: 10.1007/s10311-013-0427-1.

9. Inagaki, S., Caretta, T., Alfaya, R.V. \& Alfaya, A. (2013). Mexerica mandarin (Citrus nobilis) peel as a new biosorbent to remove $\mathrm{Cu}(\mathrm{II}), \mathrm{Cd}(\mathrm{II})$, and $\mathrm{Pb}(\mathrm{II})$ from industrial effluent. Desalin. Water Treat. 51(28-30), 5537-5546. DOI: 10.1080/19443994.2012.759156.

10. Şahin, İ., Keskin, S.Y. \& Keskin, C.S. (2013). Biosorption of cadmium, manganese, nickel, lead, and zinc ions by Aspergillus tamari. Desalin. Water Treat. 51(22-24), 4524-4529. DOI: 10.1080/19443994.2012.752332.

11. Meena, A.K., Kadirvelu, K., Mishraa, G.K., Rajagopal, C. \& Nagar, P.N. (2008). Adsorption of $\mathrm{Pb}(\mathrm{II})$ and $\mathrm{Cd}(\mathrm{II})$ metal ions from aqueous solutions by mustard husk. J. Hazard. Mater. 150(3), 619-625. DOI: 10.1016/j.jhazmat.2007.05.011.

12. Thakur, V.K. \& Thakur, M.K. (2015). Recent advances in green hydrogels from lignin: A review. Int. J. Biol. Macromol. 72, 834-847. DOI: 10.1016/j.ijbiomac.2014.09.044.

13. Thakur, V.K., Thakur, M.K. \& Gupta, R.K. (2014). Review: Raw natural fiber-based polymer composites. Int. J. Polym. Anal. Character. 19(3), 256-271. DOI: 10.1080/1023666X.2014.880016. 14. Thakur, V.K., Thakur, M.K., Raghavan, P. \& Kessler M.R. (2014). Progress in green polymer composites from lignin for multifunctional applications: A review. ACS Sustainable Chem. Eng. 2(5), 1072-1092. DOI: 10.1021/sc500087z.

15. Betancur, M., Bonelli, P.R., Velásquez, J.A. \& Cukierman, A.L. (2009). Potentiality of lignin from the Kraft pulping process for removal of trace nickel from wastewater: Effect of demineralization. Bioresour. Technol. 100(3), 1130-1137. DOI: 10.1016/j.biortech.2008.08.023.

16. Bulgariu, L., Bulgariu, D., Malutan, T. \& Macoveanu, M. (2009). Adsorption of lead(II) ions from aqueous solution onto lignin. Adsorp. Sci. Technol. 27(4), 435-445. DOI: 10.1260/026361709790252623.

17. Guo, X., Zhang, S. \& Shan, X. (2008). Adsorption of metal ions on lignin. J. Hazard. Mater. 151(1), 134-142. DOI: 10.1016/j.jhazmat.2007.05.065. 
18. Ahmaruzzaman, M. (2011). Industrial wastes as low-cost potential adsorbents for the treatment of wastewater laden with heavy metals. Adv. Colloid Interface Colloid Interface Colloid Interface Sci. 166(1-2), 36-59. DOI: 10.1016/j.cis.2011.04.005.

19. Lei, Y. \& Huizhen, Y. (2013). Modification of reed alkali lignin to adsorption of heavy metals. Adv. Mater. Res. 622(1), 1646-1650. DOI: 10.4028/www.scientific.net/AMR.622-623.1646. 20. Ge, Y., Li, Z., Kong, Y., Song, Q. \& Wang, K. (2014). Heavy metal ions retention by bi-functionalized lignin: Synthesis, applications, and adsorption mechanisms. J. Ind. Eng. Chem. 20(6), 4429-4436. DOI: 10.1016/j.jiec.2014.02.011.

21. Klapiszewski, Ł., Nowacka, M., Milczarek, G. \& Jesionowski, T. (2013). Physicochemical and electrokinetic properties of silica/lignin biocomposites. Carbohydr. Polym. 94(1), 345-355. DOI: 10.1016/j.carbpol.2013.01.058.

22. Jesionowski, T., Klapiszewski, Ł. \& Milczarek, G. (2014).

Kraft lignin and silica as precursors of advanced composite materials and electroactive blends. J. Mater. Sci. 49(3), 1376-1385. DOI: $10.1007 / \mathrm{s} 10853-013-7822-7$.

23. Klapiszewski, Ł., Bartczak, P., Wysokowski, M., Jankowska, M., Kabat, K. \& Jesionowski, T. (2015). Silica conjugated with kraft lignin and its use as a novel 'green' sorbent for hazardous metal ions removal. Chem. Eng. J. 260, 684-693. DOI: 10.1016/j.cej.2014.09.054.

24. Jesionowski, T., Klapiszewski, Ł. \& Milczarek, G. (2014). Structural and electrochemical properties of multifunctional silica/lignin materials. Mater. Chem. Phys. 147(3), 1049-1057. DOI: 10.1016/j.matchemphys.2014.06.058.

25. Jesionowski, T. \& Krysztafkiewicz, A. (2000). Comparison of the techniques used to modify amorphous hydrated silicas. J. Non-Cryst. Sol. 277(1), 45-57. DOI: 10.1016/S00223093(00)00299-4.

26. Jesionowski, T., Ciesielczyk, F. \& Krysztafkiewicz, A. (2010). Influence of selected alkoxysilanes on dispersive properties and surface chemistry of spherical silica precipitated in emulsion media. Mater. Chem. Phys. 119(1-2), 65-74. DOI: 10.1016/j. matchemphys.2009.07.034.

27. Lagergren, S. (1898). About the theory of so-called adsorption of soluble substances. Kungliga. Svenska. Vetensk. Handl. 24, 1-39.

28. Ho, Y.S. \& McKay, G. (1999). Pseudo-second order model for sorption processes. Process Biochem. 34(5), 451-465. DOI: 10.1016/S0032-9592(98)00112-5.

29. Freundlich, H.M.F. (1906). Over the adsorption in solution. J. Phys. Chem. 57(A), 385-470.

30. Langmuir, I. (1918). The adsorption of gases on plane surfaces of glass, mica and platinum. J. Am. Chem. Soc. 40(9), 1361-1403.

31. Kumari, M., Pittman, Jr C.U. \& Mohan, D. (2015). Heavy metals [chromium (VI) and lead (II)] removal from water using mesoporous magnetite $\left(\mathrm{Fe}_{3} \mathrm{O}_{4}\right)$ nanospheres. J. Colloid Interface Sci. 442, 120-132. DOI: 10.1016/j.jcis.2014.09.012.

32. Ma, S., Chen, Q., Li, H., Wang, P., Islam, S.M., Gu, Q., Yanga, X. \& Kanatzidis, M.G. (2014). Highly selective and efficient heavy metal capture with polysulfide intercalated layered double hydroxides. J. Mater. Chem. A 2(26), 10280-10289. DOI: $10.1039 / \mathrm{C} 4 \mathrm{TA} 01203 \mathrm{H}$. 